\title{
STRATEGI KEUNGGULAN BERSAING DALAM MENINGKATKAN KINERJA PEMASARAN DIMASA PANDEMI COVID-19 (Studi pada Peternakan UD.Baqoroh Joyo, Sidoarjo Jawa Timur)
}

\author{
'Mujita Fajar Nataraningtyas, ${ }^{2}$ Lisa Sulistyawati \\ 1,2 Program Studi Admistrasi Bisnis Fakultas IImu Sosial dan IImu Politik \\ 1,2 Universitas Pembangunan Nasional "veteran" Jawa Timur \\ Email: ' mujitanataraningtyas40541@gmail.com, ${ }^{2}$ lisa adi50@yahoo.com
}

Surabaya, 60294, Indonesia

\begin{abstract}
This research was conducted with the aim of knowing and analyzing competitive advantage strategies in improving marketing performance implemented by UD. Baqoroh Joyo during the covid-19 pandemic, to find out and analyze marketing performance during the covid-19 pandemic. The research method used is descriptive qualitative method with SWOT analysis method and data collection techniques through deep interviews, surveys, observations, questionnaires and documentation in identifying strengths, weaknesses, opportunities and threats at UD. Baqoroh Joyo. Based on the calculation of the results of IFAS EFAS shows that UD. Baqoroh Joyo has IFAS results with a strength score of 2.87 and a weakness score of 0.28 , while the EFAS results show an opportunity score of 2.63 and a threat score of 0.43 . Based on the diagram, the results of the SWOT analysis show that UD. Baqoroh Joyo is in Quadrant I with a SO (Strength Opportunity) strategy. In this situation it means UD. Baqoroh Joyo The company must maximize and use its strengths and opportunities to strengthen its position. So that the strategy that can be applied can support an aggressive growth policy (growth oriented strategy) in improving marketing performance during the COVID-19 pandemic.
\end{abstract}

Keywords: Competitive advantage strategy; SWOT analysis

\begin{abstract}
Abstrak
Penelitian ini dilakukan bertujuan Untuk mengetahui dan menganalisis strategi keunggulan bersaing dalam meningkatkan kinerja pemasaran yang diterapkan oleh UD.Bagoroh Joyo dimasa pandemi covid-19, Untuk mengetahui dan menganalisis kinerja pemasaran selama pandemic covid-19. Metode penelitian yang digunakan adalah dengan menggunakan metode kualitatif deskriptif dengan metode analisis SWOT dan teknik pengumpulan data melalui wawancara mendalam (deep interview), survey, observasi, kuisioner serta dokumentasi dalam mengidentifikasi kekuatan, kelemahan, peluang dan ancaman pada UD. Baqoroh Joyo. Berdasarkan perhitungan hasil IFAS EFAS menunjukan bahwa UD. Baqoroh Joyo memiliki hasil IFAS nilai skor kekuatan sebesar 2,87 dan skor kelemahan sebesar 0,28 sedangkan hasil EFAS menunjukan skor peluang sebesar 2,63 dan skor ancaman 0,43. Berdasarkan diagram hasil analisis SWOT menunjukan bahwa UD. Baqoroh Joyo berada pada Kuadran I dengan strategi SO (Strength Opportunity), Pada situasi ini berarti UD. Baqoroh Joyo Perusahaan harus memaksimalkan dan menggunakan kekuatan dan peluang yang dimiliki untuk memperkuat posisi tersebut. Sehingga strategi ynag dapat diterpkan dapat mendukung kebijakan pertumbuhan yang agresif (growth oriented strategy) dalam meningkatkan kinerja pemasaran dimasa pandemi covid-19.
\end{abstract}

Kata Kunci: Strategi keunggulan bersaing; Analisis SWOT

Open Access at:http://ois.uho.ac.id/index.php/PUBLICUHO/index

Journal Publicuho is licensed under a Creative Commons Attribution 4.0 International License. 
ISSN 2621-1351 (online), ISSN 2685-0729 (print)

Volume 5 Number 1 (February - April 2022), pp.1-14

DOI:http://dx.doi.org/10.35817/jpu.v5i1.23469

Mujita Fajar nataraningtyas, Lisa Sulistyawati

\section{PENDAHULUAN}

Di era persaingan saat ini setiap perusahaan baik perusahaan besar maupun perusahaan kecil selalu berupaya agar usahanya dapat berlangsung dalam jangka waktu yang lama bahkan tetap survival terlebih di tengah pandemic covid-19. Kelangsungan perusahaan dapat dicapai melalui salah satunya pemanfaatan peluang yang ada. Ketatnya persaingan dalam dunia usaha membuat owner dan manajer berfikir bagaimana cara agar tetap bisa memenuhi kebutuhan dan keinginan konsumen baik berupa produk atau jasa. Dengan demikian maka diperlukan adanya strategi yang tepat. Strategi merupakan aspek yang penting bagi perusahaan yang mana strategi adalah sebuah cara atau taktik yang dirancang oleh perusahaan yang dinilai efektif guna tercapainya tujuan perusahaan yang diinginkan. Keunggulan bersaing adalah suatu keuntungan yang diperoleh lebih dari pesaing dengan menawarkan pelanggan nilai yang lebih besar, baik melalui harga yang lebih rendah atau dengan memberikan manfaat tambahan dan layanan pada harga yang lebih tinggi (Richad Vernando, 2020). Terdapat tiga indikator strategi generik keunggulan bersaing menurut Michael Porter dalam Richad Vernando 2020 :

\section{Strategi Keunggulan Biaya}

Strategi kenggulan biaya merupakan sebuah strategi yang menekankan pada pembuatan produk standar dengan biaya per unit sangat rendah untuk konsumen yang peka terhadap perubahan biaya.Terdapat dua strategi alternative kepemimpinan biaya, yaitu strategi biaya rendah (low-cost) yang menawaarkan produk atau jasa kepada konsumen pada harga terendah yang tersedia di pasar. Strategi nilai terbaik (best-value) yang menawarkan produk atau jasa kepada konsumen dengan nilai harga terbaik yang tersedia di pasar.

\section{Strategi Diferensiasi}

Strategi diferensiasi adalah strategi dengan tuajuan membuat produk dan menyediakan jasa yang dianggap unik di seluruh industri dan ditujukan kepada konsumen yang relative tidak peduli terhadap perubahan harga. Seringkali berhubungan dengan inovasi, tetapi perusahaan juga harus memperbaiki proses edukasi/berproduksi dengan cara yang baru yang lebih efisien serta efektif. Cara baru tersebut tidak hanya membuat perusahaan lebih unggul dari segi produk tetapi juga berhubungan dengan semakin sulitnya bagi pihak pesaing untuk meniru.

\section{Strategi fokus}

Rahayu puji suci (2015) mengatakan bahwa "Strategi fokus merupakan strategi yang membuat produk dan menyediakan jasa yang memenuhi keperluan sejumlah kelompok 


\section{Journal Publicuho}

ISSN 2621-1351 (online), ISSN 2685-0729 (print)

Volume 5 Number 1 (February - April 2022) pp. 1-14

Accredited SINTA SK.NOMOR 28/E/KPT/2019

Open Access at:http://ojs.uho.ac.id/index.php/PUBLICUHO/index

DOI: http://dx.doi.org/10.35817/jpu.v5i1.23469

kecil konsumen, strategi didasarkan pada usaha memenuhi kebutuhan khususnya dari pelanggan, dengan lini produk yang sedikit"'.

Usaha Mikro Kecil Menengah (UMKM) merupakan salah satu bagian penting dari perekonomian suatu negara, Peran penting tersebut mendorong negara berkembang untuk terus mengupayakan pengembangan Usaha Mikro Kecil Menengah (UMKM) Salah satu jenis usaha yang menjanjikan dengan potensi keuntungan lumayan besar adalah bisnis peternakan. Peternakan sapi perah merupakan salah satu dibidang peternakan yang memiliki peran strategis dalam memenuhi pangan yang terus meningkat, peningkatan pendapatan penduduk dan peningkatan perekonomian nasional. Pengembangan sapi perah telah mendorong terciptanya peternakan berkelanjutan, penyediaan protein hewani bagi masyarakat, penyediaan bahan baku industry dan penambahan lapangan kerja.

Tabel 1. Data peternakan susu sapi perah di Sidoarjo data pusat statistic Sidoarjo

\begin{tabular}{lc}
\hline \multicolumn{1}{c}{ Nama peternakan } & Alamat \\
\hline Peternakan sapi perah Chaqiai & $\begin{array}{l}\text { J. Sawunggaling Timur No.14 Sambikerep, } \\
\text { Jemundo,Kec. Taman Kab. Sidoarjo 61257 }\end{array}$ \\
\hline Peternakan Sapi perah Suryadi & Desa plaosan,kec. Wonoayu,Sidoarjo \\
\hline Peternakan sapi perah "Drajat Farm" & Jl. Karangnongko,karangpuri RT 02 RW 04 Kec. \\
& Wonoayu,Kab. Sidoarjo 61261 \\
\hline $\begin{array}{l}\text { Peternakan sapi perah "Sumber waras } \\
\text { dairy farm" }\end{array}$ & $\begin{array}{c}\text { Jl. Pattimura IV No.5 Menyanggong, kletek } \\
\text { kec.Taman, Kab.Sidoarjo }\end{array}$ \\
\hline Peternakan susu sapi pak ridwan & $\begin{array}{c}\text { Perumahan pondok jati blok BW 03 Jati,Kec. } \\
\text { Sidoarjo Kab. Sidoarjo 61212 }\end{array}$ \\
\hline Kampoeng ternak STMJ & JI.Ngelom megare RT 02 RW 01 Kec.Taman Kab. \\
& Sidoarjo Jawa Timur 61257
\end{tabular}

Direktorat jendral peternakan (2010) mengatakan permintaan susu nasional $80 \%$ masih diimpor diluar negeri. Hal ini memberikan peluang bagi peternak untuk meningkatkan populasi dan produktivitas sapi perah dalam negeri serta mengurangi ketergantungan impor. Saat ini ditengah pandemi COVID-19 asupan makanan dan minuman bergizi tinggi sangat diperlukan untuk memperkuat daya tahan tubuh salah satunya melalui konsumsi susu, mengingat banyaknya manfaat yang diperoleh diantaranya untuk pertumbuhan yaitu regenerasi sel, penguatan tulang dan gigi, menyokong pertumbuhan fisik, meningkatkan kecerdasan dan juga dapat meningkatkan imunitas tubuh sehingga meminimalisir potensi terinfeksi agen penyakit. 
ISSN 2621-1351 (online), ISSN 2685-0729 (print)

Volume 5 Number 1 (February - April 2022), pp.1-14

Mujita Fajar nataraningtyas, Lisa Sulistyawati DOl:http://dx.doi.org/10.35817/jpu.v5i1.23469

Tabel 2. data penjualan susu sapi UD.Baqoroh Joyo Sidoarjo Periode Januari-Agustus 2021

\begin{tabular}{cccc}
\hline NO & BULAN & LITER & PENJUALAN \\
\hline 1 & Januari & 5.100 Liter & Rp. 51.000 .000 \\
\hline 2. & Februari & 7.050 Liter & Rp. 70.500 .000 \\
\hline 3. & Maret & 8.700 Liter & Rp. 87.000 .000 \\
\hline 4. & April & 8.700 Liter & Rp. 87.000 .000 \\
\hline 5. & Mei & 9.300 Liter & Rp. 93.000 .000 \\
\hline 6. & Juni & 11.250 Liter & Rp. 112.500 .000 \\
\hline 7. & Juli & 12.000 Liter & Rp. 120.000 .000 \\
\hline 8. & Agustus & 10.500 Liter & Rp. 105.000 .000 \\
\hline
\end{tabular}

Berdasarkan pernyataan diatas menjadi sumber permintaan yang semakin meningkat terhadap produksi susu sapi untuk memenuhi kebutuhan dan konsumsi masyarakat. Penjualan peternakan susu sapi UD.Baqoroh joyo, Sidoarjo mengalami peningkatan yang cukup baik dan dapat bertahan dimasa pandemi. Pada bulan januari 2021 peternakan UD. Baqoroh Joyo mampu menghasilkan 200 Liter tiap harinya, sebelumnya hanya memproduksi 100 Liter perharinya, proses pemerahan susu sapi terjadi disetiap harinya jika diakumulasikan dalam 1 bulan (30 hari) maka pada bulan januari mampu menghasilkan 5.100 Liter. Dijual harga perliternya Rp. 10.000 untuk susu sapi mentah sehingga pada bulan Januari 2021 UD.Baqoroh Joyo mendapatkan pendapatan penjualan sebesar Rp. 51.000.000, dan terus terjadi peningkatan yang signifikan hinga puncaknya pada bulan Juli 2021 dan mendapatkan omset penjualan sebanyak Rp.120.000.000 dengan penjualan 12.000 Liter. Hal tersebut dilatar belakangi oleh terjadinya fenomena panic buying susu pateurisasi bear brand saat pandemic covid-19. Karena adanya peningkatan kebutuhan masyarakat Indonesia di tengah pandemi COVID-19 sedangkan di pasaran susu tersebut habis dan tidak mudah ditemukan, Kelangkaan tersebut membuat masyarakat di Sidoarjo lebih memilih untuk membeli susu sapi murni di UD.Baqoroh Joyo karena harga lebih murah, namun pada bulan Agustus 2021 mengalami penurunan, hal ini dikarenakan adanya edukasi dari media online dan dokter lainnya yang mengatakan bahwa semua susu mempunyai kandungan dan manfaat yang sama dalam memperkuat daya tahan tubuh dan bagi kesehatan.Sehingga masyarakat kembali mengonsumsi susu yang siap minum seperti di supermarket-supermarket.

Oleh karena itu Untuk mengetahui strategi keunggulan bersaing yang paling tepat adalah menggunakan metode yang merumuskan suatu strategi pengembangan usaha yakni analisis SWOT. Analisis SWOT membandingkan antara factor eksternal peluang (opportunity) dan ancaman (threats) dengan factor internal kekuatan (strength) dan kelemahan (weakness). (Freddy Rangkuti 2016:19 Analisis ini didasarkan pada kemampuan perusahaan dalam memanfaatkan kesempatan (opportunities) yang berlandaskan pada kekuatan (strenghts) yang dimiliki perusahaan, mengatasi ancaman (threat) yang datang dari luar 


\section{Journal Publicuho}

ISSN 2621-1351 (online), ISSN 2685-0729 (print)

Volume 5 Number 1 (February - April 2022) pp. 1-14

Accredited SINTA SK.NOMOR 28/E/KPT/2019

Open Access at:http://ojs.uho.ac.id/index.php/PUBLICUHO/index

DOI: http://dx.doi.org/10.35817/jpu.v5i1.23469

serta memperbaiki kelemahan (weaknesses) yang ada. Dan hasil dari analisis SWOT dapat dirumuskan suatu strategi keunggulan bersaing dalam meningkatkan kinerja pemasaran yang tepat sehingga dapat meningkatkan omzet penjualan. Dengan menggunakan analisis SWOT UD.Baqoroh Joyo lebih dimudahkan dalam melakukan tinjauan kembali, pertimbangan atau kebijakan dan evaluasi pemilik Usaha Mikro Kecil Menengah (UMKM) Peternakan UD.Baqoroh Joyo dalam mengambil kebijakan dan pemecahan masalah mengenai strategi keunggulan bersaing yang digunakan oleh UD.Baqoroh Joyo.Juga sebagai masukan/pertimbangan dalam upaya peningkatan kinerja serta dapat menjadi referensi dalam pengambilan keputusan bisnis.

\section{METODOLOGI}

Pendekatan penelitian yang digunakan dalam penelitian ini adalah pendekatan kualitatif dengan dengan menggunakan metode kualitatif deskriptif. Deskriptif kualitatif yaitu data yang dikumpulkan berupa kata-kata, gambar, dan angka melalui pengumpulan data, analisis, kemudian diintrepetasikan. Metodologi adalah proses, prinsip dan prosedur yang digunakan untuk mendekati problem dan mencari jawaban. Data penelitian kualitatif diperoleh melalui wawancara mendalam, catatan lapangan,hasil observasi dan studi dokumentasi. Penelitian ini dilakukan di peternakan UD.Baqoroh Joyo yang terletak di dusun Cemengkalang, desa Cemengkalang, Kecamatan Sidoarjo, Kabupaten Sidoarjo Jawa Timur 61234. Dalam penelitian kualitatif ini tidak menggunakan populasi sebab penelitian kualitatif berangkat dari kasus tertentu. Sampel didalam penelitian kualitatif tidak dinamakan responden tetapi sebagai narasumber atau partisipan, informan, teman dan guru dalam penelitian. Dengan demikian berdasarkan pelaksanaan pengambilan sampel selama 1 bulan sesuai uraian diatas populasi sampel dalam penelitian kualitatif ini dapat diketahui yaitu pemilik, karyawan serta konsumen yang telah mengonsumsi produk dari UD.Baqoroh Joyo.

Teknik pengumpulan ini dilakukan melalui Wawancara ( in-depth interview), Survei, Observasi, Studi kepustakaan dan Kuisioner. Penelitian ini menggunakan dua sumber data yang berkaitan dengan pengumpulan data yakni Sumber data primer dan sekunder. Teknik Analisis Data dalam penelitian ini adalah menggunakan metode pendekatan kualitatif deskriptif dan analisis mengunakan SWOT. Data data kualitatif dihasilkan dalam wawancara mendalam (indept interview) yang berkaitan dengan strategi keunggulan bersaing UMKM UD.Baqoroh Joyo dalam menghadapi masa pandemi yang berada di di dusun Cemengkalang desa Cemengkalang rt 05 rw 02, Kecamatan Sidoarjo, Kabupaten Sidoarjo Jawa Timur 61234 Indonesia dalam mengembangkan usahanya. 
ISSN 2621-1351 (online), ISSN 2685-0729 (print)

Langkah-langkah pembuatan analisis Swot:

1.) Internal Facktor Anlysis Summary (IFAS)

Analisis internal diperlukan dalam menyusun strategi untuk memaksimalkan keuatan dan meminimalkan kelemahan. Untuk mengevaluasi faktor-faktor tersebut, perlunya analisis faktor-faktor internal apa saja yang meliputi menjadi kekuatan dan kekurangan perusahaan sebelum mengidentifikasi faktor eksternal perusahaan.

2.) External Factor Analysis Summary (EFAS)

Setelah mengetahui faktor internal dilanjutkan dengan Analisis External Factor Analysis Summary(EFAS). Matriks EFAS merupakan analisis terhadap faktor-faktor eksternal perusahaan untuk mengetahui apa saja yang menjadi peluang dan ancaman perusahaan. Analisis eksternal diperlukan dalam menyusun strategi untuk memanfaatkan kesempatan/peluang dan menghindari ancaman.

3.) Perhitungan matriks IFAS dan EFAS

Perhitungan matriks IFAS dan EFAS pada analisis SWOT dengan menggunakan cara sebagai berikut :

1. perhitungan bobot factor internal dan eksternal
a. Bobot faktor internal
$=\frac{\text { total jawaban responden }}{\text { total pengolahan data faktor internal }}$
b. Bobot faktor external
$=\frac{\text { total jawaban responden }}{\text { total pengolahan data faktor eksternal }}$

2. Perhitungan rating faktor internal dan eksternal
a. Rating faktor internal
$=\frac{\text { total jawaban responden }}{\text { jumlah responden }}$
b. Rating faktor eksternal
$=\frac{\text { total jawaban responden }}{\text { jumlah responden }}$

3. Perhitungan skor factor internal dan eksternal
a. Skor IFAS = Bobot factor internal $\times$ Rating factor internal
b. Skor EFAS = Bobot factor internal $\times$ Rating factor internal

4.) Perencanaan kombinasi Matriks analisis SWOT

Setelah menganalisis faktor-faktor strategi internal dan eksternal perusahaan melalui tabel IFAS dan EFAS kemudian dilanjutkan dengan penentuan strategi SO,ST,WO dan WT. 


\section{Journal Publicuho}

ISSN 2621-1351 (online), ISSN 2685-0729 (print)

Volume 5 Number 1 (February - April 2022) pp. 1-14

Accredited SINTA SK.NOMOR 28/E/KPT/2019

Open Access at:http://ojs.uho.ac.id/index.php/PUBLICUHO/index

DOI: http://dx.doi.org/10.35817/jpu.v5il.23469

\section{HASIL DAN PEMBAHASAN}

Analisis swot terhadap UD. Baqoroh Joyo Analisis SWOT dapat digunakan untuk menganalisa, membandingkan antara faktor eksternal peluang (opportunity) dan ancaman (threats) dengan faktor internal kekuatan (strength) dan kelemahan (weakness). Dalam hal ini kesempatan (opportunities) yang berlandaskan pada kekuatan (strenghts) yang dimiliki perusahaan, mengatasi ancaman (threat) yang datang dari luar serta memperbaiki kelemahan (weaknesses) yang ada. Analisis ini berdasarkan hasil wawancara dengan para informan dalam penelitian pada UD. Baqoroh Joyo Sidoarjo adalah sebagai berikut :

Hasil Analisis IFAS (Internal Factor Anlysis Summary)

Tabel 3. Hasil Analisis IFAS (Internal Factor Anlysis Summary)

\begin{tabular}{|c|c|c|c|c|c|c|}
\hline NO & Faktor - Faktor Strategi Internal & Jumlah & Bobot & Rating & BxR & Komentar \\
\hline $\mathbf{A}$ & KEKUATAN & & & & & \\
\hline 1. & $\begin{array}{l}\text { Memberikan produk yang } \\
\text { berkualitas kepada konsumen } \\
\text { dengan rasa yang enak dan } \\
\text { terbuat dari susu alami juga } \\
\text { terdapat label halal MUI }\end{array}$ & 115 & 0,14 & 4 & 0,56 & $\begin{array}{llr}\text { Kualitas } & \text { produk } & \text { dapat } \\
\text { dibuktikan keaslianya } & \text { dan } \\
\text { layak konsumsi karena } & \text { sudah } \\
\text { berstandart } & \text { MUI. }\end{array}$ \\
\hline 2. & $\begin{array}{l}\text { Harga yang ditawarkan } \\
\text { tergolong murah dan terjangkau }\end{array}$ & 111 & 0,13 & 4 & 0,52 & $\begin{array}{l}\text { Harga yang ditawarkan oleh } \\
\text { UD. Baqoroh Joyo cukup } \\
\text { kompetitif dimasa pandemi }\end{array}$ \\
\hline 3. & Lokasi Usaha Yang Strategis & 100 & 0,12 & 3 & 0,36 & $\begin{array}{l}\text { Lokasi UD. Baqoroh Joyo } \\
\text { strategis karena terletak di } \\
\text { dekat alun-alun Sidoarjo, dekat } \\
\text { dengan kecamatan dan } \\
\text { tempat kandangnya tidak jauh } \\
\text { dari jalan raya hal itu membuat } \\
\text { UD. Baqoroh Joyo mudah } \\
\text { dikenali dan ditemukan oleh } \\
\text { masyarakat. }\end{array}$ \\
\hline 4. & $\begin{array}{l}\text { Fasilitas yang diberikan } \\
\text { perusahaan kepada konsumen } \\
\text { tersedia seperti wisata edukasi } \\
\text { sapi perah. }\end{array}$ & 109 & 0,13 & 4 & 0,52 & $\begin{array}{llr}\text { Sarana } & \text { dan } & \text { Prasarana } \\
\text { kandang dapat berfungsi } \\
\text { maksimal. Adanya fasilitas } \\
\text { untuk edukasi wisata sapi } \\
\text { perah. }\end{array}$ \\
\hline 5. & $\begin{array}{l}\text { Susu yang ditawarkan memiliki } \\
\text { berbagai varians rasa seperti } \\
\text { original, vanilla, strawberry, } \\
\text { coklat, mocca, dan melon }\end{array}$ & 111 & 0,13 & 4 & 0,52 & $\begin{array}{l}\text { Banyaknya varians rasa yang } \\
\text { diberikan membuat konsumen } \\
\text { tidak bosan dan ingin } \\
\text { merasakan varian yang } \\
\text { lainnya. }\end{array}$ \\
\hline 6. & $\begin{array}{l}\text { Pelayanan yang diberikan } \\
\text { kepada customer ramah dan } \\
\text { baik }\end{array}$ & 107 & 0,13 & 3 & 0,39 & $\begin{array}{l}\text { Melayani dengan ramah, dan } \\
\text { tepat waktu. }\end{array}$ \\
\hline & TOTAL & 653 & 0,78 & & 2,87 & \\
\hline B & KELEMAHAN & & & & & \\
\hline 1. & $\begin{array}{l}\text { Masa Penyimpanan Susu Tidak } \\
\text { Bisa Lama }\end{array}$ & 41 & 0,05 & 1 & 0,05 & $\begin{array}{l}\text { Masa penyimpanan susu tidak } \\
\text { dapat bertahan lama karena } \\
\text { tidak menggunakan bahan } \\
\text { pengawet. }\end{array}$ \\
\hline 2. & $\begin{array}{l}\text { Kurangnya Penguasaan } \\
\text { Teknologi sehingga pemasaran } \\
\text { digital kurang maksimal }\end{array}$ & 51 & 0,06 & 1 & 0,06 & $\begin{array}{l}\text { Kurangnya penguasaan } \\
\text { teknologi dalam pemasaran } \\
\text { sehingga promosi yang kurang }\end{array}$ \\
\hline
\end{tabular}


STRATEGI KEUNGGULAN BERSAING DALAM MENINGKATKAN KINERJA PEMASARAN DIMASA PANDEMI COVID-19 (Studi pada Peternakan UD.Baqoroh Joyo, Sidoarjo Jawa Timur)

ISSN 2621-1351 (online), ISSN 2685-0729 (print)

Volume 5 Number 1 (February - April 2022), pp.1-14

Mujita Fajar nataraningtyas, Lisa Sulistyawati

DOI:http://dx.doi.org/10.35817/jpu.v5i1.23469

\begin{tabular}{|c|c|c|c|c|c|c|}
\hline NO & Faktor - Faktor Strategi Internal & Jumlah & Bobot & Rating & BXR & Komentar \\
\hline & & & & & & maksimal. \\
\hline 3. & $\begin{array}{l}\text { Sistem Manajerial Perusahaan } \\
\text { Kurang Terstuktur, karena } \\
\text { sebagian besar ditangani oleh } \\
\text { pemilik dan keluarga. }\end{array}$ & 46 & 0,05 & 1 & 0,05 & $\begin{array}{l}\text { Sistem manajerial yang ada di } \\
\text { UD. Baqoroh Joyo yang kurang } \\
\text { maksimal, karena tidak adanya } \\
\text { pembagian jobdesc }\end{array}$ \\
\hline 45. & $\begin{array}{l}\text { Produktivitas sapi terbatas. (Tidak } \\
\text { selamanya sapi bisa untuk } \\
\text { memproduksi susu) }\end{array}$ & 50 & 0,06 & 2 & 0,12 & $\begin{array}{l}\text { Semua sapi perah tidak } \\
\text { semuanya produktif sehingga. }\end{array}$ \\
\hline & TOTAL & 188 & 0,22 & & 0,28 & \\
\hline & TOTAL IFAS & 841 & 1 & & 3,15 & \\
\hline
\end{tabular}

Sumber : Hasil olah data peneliti 2022

Hasil Analisis EFAS (external Factors Anlysis Summary)

Tabel 4. Hasil Analisis EFAS (External Factors analysis summary)

\begin{tabular}{lllllll}
\hline No. & $\begin{array}{c}\text { Faktor-Faktor Strategi } \\
\text { Eksternal }\end{array}$ & Jumlah & Bobot & Rating & B X R & Komentar \\
\hline A. & PELUANG & & & & \\
\hline 1. & $\begin{array}{l}\text { Adanya anjuran pemerintah } \\
\text { untuk mengonsumsi susu sapi } \\
\text { sebelum dan selama } \\
\text { pandemi guna menjaga dan }\end{array}$ & 0,19 & 4 & 0,76 & $\begin{array}{c}\text { Adanya ajakan pemerintah } \\
\text { selama } \\
\text { pandemi untuk }\end{array}$ \\
& & & & mengonsumsi susu sapi.
\end{tabular}
meningkatkan imun tubuh

\begin{tabular}{|c|c|c|c|c|c|c|}
\hline 2. & $\begin{array}{lr}\text { Dukungan } & \text { pemerintah } \\
\text { daerah } & \text { (dukungan } \\
\text { perizinan,pemasaran produk) }\end{array}$ & 108 & 0,19 & 4 & 0,76 & $\begin{array}{l}\text { Pemerintah Kab. Sidoarjo } \\
\text { memberikan wadah bagi } \\
\text { para pengelola peternakan } \\
\text { untuk mengikuti kegiatan } \\
\text { yang diadakan oleh } \\
\text { pemerintah. }\end{array}$ \\
\hline
\end{tabular}

\begin{tabular}{lllllll}
\hline 3. & $\begin{array}{l}\text { Tingkat } \\
\text { manusia } \\
\text { tahunnya }\end{array}$ & $\begin{array}{c}\text { pertumbuhan } 104 \\
\text { meningkat tiap }\end{array}$ & 0,18 & 3 & 0,54 & $\begin{array}{l}\text { Kebutuhan nutrisi akan susu } \\
\text { sapi juga meningkat. }\end{array}$ \\
\hline 4. & $\begin{array}{l}\text { Fenomena Panic Buying } 107 \\
\text { Pembelian Susu Sapi }\end{array}$ & 0,19 & 3 & 0,57 & $\begin{array}{l}\text { Maraknya covid-19 membuat } \\
\text { masyarakat berlomba-lomba } \\
\text { untuk mendapatkan susu sapi } \\
\text { murni. }\end{array}$
\end{tabular}

\begin{tabular}{|c|c|c|c|c|c|c|}
\hline & TOTAL & 431 & 0,75 & & 2,63 & \\
\hline B. & ANCAMAN & & & & & \\
\hline 1. & $\begin{array}{l}\text { Banyaknya pesaing sejenis } \\
\text { yang memiliki harga lebih } \\
\text { rendah dan produk yang } \\
\text { sama }\end{array}$ & 42 & 0,07 & 1 & 0,07 & $\begin{array}{l}\text { Banyak pesaing sejenis dan } \\
\text { supermarket }\end{array}$ \\
\hline 2. & $\begin{array}{lr}\text { Kebijakan } & \text { pemerintah } \\
\text { selama } & \text { pandemi } \\
\text { menghambat operasi bisnis }\end{array}$ & 52 & 0,09 & 2 & 0,18 & $\begin{array}{l}\text { Adanya kebijakan PSBB, dan } \\
\text { PPKM }\end{array}$ \\
\hline \multirow[t]{3}{*}{3.} & $\begin{array}{lr}\text { Biaya operasional } & \text { selama } \\
\text { pandemi } & \text { covid-19 } \\
\text { meningkat } & \\
\end{array}$ & 51 & 0,09 & 2 & 0,18 & $\begin{array}{l}\text { Biaya operasional meningkat } \\
\text { selama pandemi }\end{array}$ \\
\hline & TOTAL & 145 & 0,25 & & 0,43 & \\
\hline & TOTAL EFAS & 576 & 1 & & 3,06 & \\
\hline
\end{tabular}




\section{Journal Publicuho}

ISSN 2621-1351 (online), ISSN 2685-0729 (print)

Volume 5 Number 1 (February - April 2022) pp. 1-14

Accredited SINTA SK.NOMOR 28/E/KPT/2019

Open Access at:http://ojs.uho.ac.id/index.php/PUBLICUHO/index

DOI: http://dx.doi.org/10.35817/jpu.v5il.23469

\section{Hasil Diagram Analisis SWOT}

Dalam penentuan titik koordinat dapat dilakukan berdasarkan perhitungan sebagai berikut :

1. Titik kordinat $X$ diisi dengan analisis internal (Total skor kekuatan (S) - total skor kelemahan (W) $2,87-0,28=2,56$

2. Titik koordinat $Y$ diisi dengan analisis eksternal (total skor peluang (O) - total skor ancaman (T) $2,63-0,43=2,0$

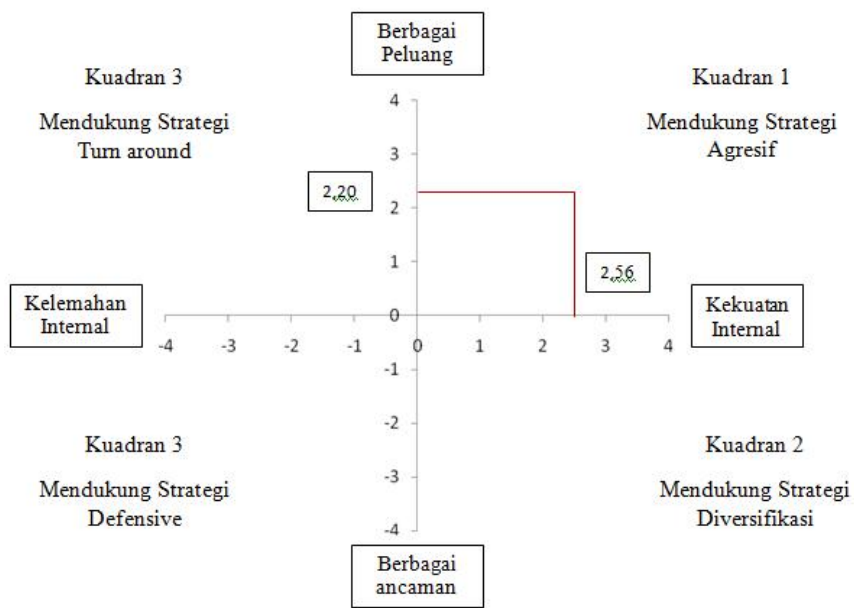

Gambar 2. Hasil diagram analisis SWOT

Sumber Sumber : Hasil olah data peneliti 2022

\section{Hasil Perencanaan Kombinasi Strategi Matriks SWOT}

Tabel 5. Hasil Perencanaan Kombinasi Strategi Matriks SWOT

\begin{tabular}{|c|c|c|}
\hline & Kekuatan (Strength) & Kelemahan (Weakness) \\
\hline EFAS & $\begin{array}{l}\text { 1. Kualitas produk yang } \\
\text { baik } \\
\text { 2. Harga yang relative } \\
\text { murah dan terjangkau } \\
\text { 3. Pengaruh lokasi usaha } \\
\text { berada di tempat yang } \\
\text { strategis baik terhadap } \\
\text { kelangsungan usaha } \\
\text { 4. Fasilitas tambahan yang } \\
\text { diberikan UD. Baqoroh } \\
\text { Joyo } \\
\text { 5. Produk susu sapi } \\
\text { mempunyai banyak } \\
\text { varians rasaa } \\
\text { 6. Pelayanan yang bagus } \\
\text { (ramah dan tanggap) }\end{array}$ & $\begin{array}{l}\text { 1. Masa penyimpanan susu } \\
\text { yang tidak lama } \\
\text { 2. Kurangnya penguasaan } \\
\text { teknologi } \\
\text { 3. Sistem manajerial yang } \\
\text { tidak maksimal dan } \\
\text { terbatasnya SDM } \\
\text { 4. Produktivitas sapi perah } \\
\text { yang tidak selamanya } \\
\text { produktif }\end{array}$ \\
\hline $\begin{array}{l}\text { Peluang ( Opportunity) } \\
\text { 1. Adanya anjuran } \\
\text { pemerintah untuk } \\
\text { mengonsumsi susu } \\
\text { 2. Dukungan pemerintah } \\
\text { daerah (dukungan perizinan }\end{array}$ & $\begin{array}{c}\text { S-O Strategy } \\
\text { (Menggunakan kekuatan } \\
\text { untuk memanfaatkan } \\
\text { peluang) } \\
\text { 1.Mempertahankan kualitas } \\
\text { produk dan Meningkatkan }\end{array}$ & $\begin{array}{l}\text { W-O Strategy } \\
\text { (Meminimalisir kelemahan } \\
\text { yang ada dengan } \\
\text { memanfaatkan peluang ) } \\
\text { 1. Meningkatkan dan } \\
\text { memperluas jangkauan }\end{array}$ \\
\hline
\end{tabular}


ISSN 2621-1351 (online), ISSN 2685-0729 (print)

\begin{tabular}{|c|c|c|}
\hline $\begin{array}{l}\text { dan pemasaran) } \\
\text { 3. Tingkat pertumbuhan } \\
\text { penduduk meningkat } \\
\text { 4. Adanya Fenomena panic } \\
\text { buying }\end{array}$ & 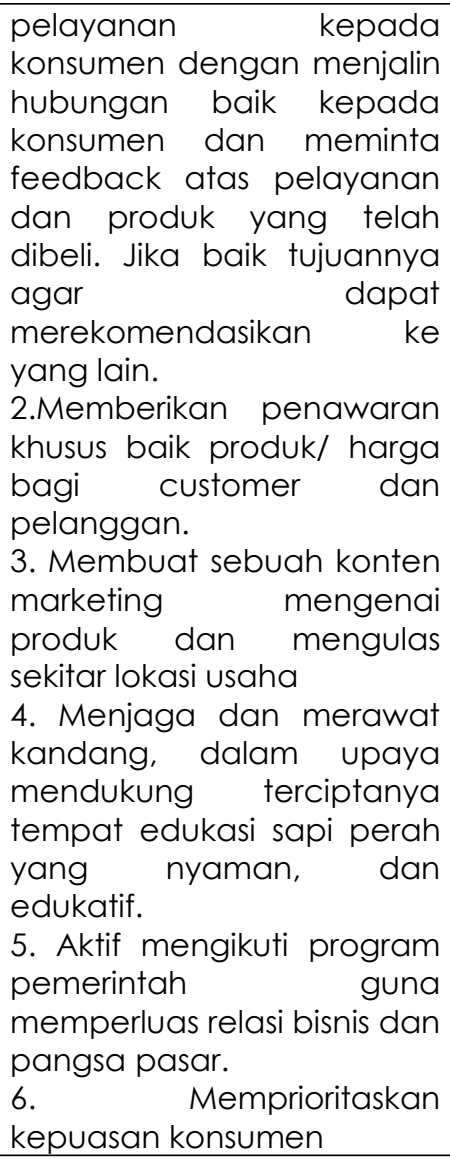 & $\begin{array}{l}\text { promosi melalui digital } \\
\text { marketing dan mouth to } \\
\text { mouth guna menunjang } \\
\text { tingkat penjualan agar } \\
\text { meningkat. } \\
\text { 2.Menambahkan showcase } \\
\text { untuk pennyimpanan } \\
\text { produk yang kebih banyak. } \\
\text { 3.Menambahkan } \\
\text { sumberdaya manusia untuk } \\
\text { memperbaiki system } \\
\text { manajerial dan mencari } \\
\text { karyawan tambahan agar } \\
\text { pembagian jobdesc jelas } \\
\text { dan tepat sasaran. } \\
\text { 4. Menerapkan sop } \\
\text { kebersihan bagi karyawan } \\
\text { 5. Memperluas jaringan } \\
\text { bisnis dengan pelaku usaha } \\
\text { dan welcome untuk bekerja } \\
\text { sama. } \\
\text { 6. Menjaga kesehatan sapi } \\
\text { perah agar selama } \\
\text { produktiv dapat maksimal } \\
\text { dalam menghasilkan susu. }\end{array}$ \\
\hline $\begin{array}{l}\text { Ancaman (Threat) } \\
\text { 1. Pesaing usaha sejenis } \\
\text { 2. Kebijakan pemerintah di } \\
\text { masa pandemi covid-19 } \\
\text { 3. Selera konsumen yang } \\
\text { dapat berubah-ubah }\end{array}$ & $\begin{array}{l}\text { S-T Strategy } \\
\text { (memanfaatkan kekuatan } \\
\text { yang dimiliki untuk } \\
\text { menghadapi ancaman) } \\
\text { 1.Memberikan penawaran } \\
\text { khusus baik produk/harga } \\
\text { bagi customer dan } \\
\text { pelanggan. } \\
\text { 2. Fokus kepada perawatan } \\
\text { dan pemeliharaan sapi } \\
\text { perah agar dapat } \\
\text { memenuhi kebutuan dan } \\
\text { ppermintaan customer. } \\
\text { 3. Menekan beberapa } \\
\text { biaya yang kurang efektif } \\
\text { agar biaya operasional } \\
\text { tidak begitu membengkak. } \\
\text { 4. Mengadakan event } \\
\text { dengan memanfaatkan } \\
\text { fasilitas yang ada untuk } \\
\text { menarik minat calon } \\
\text { konsumen. }\end{array}$ & $\begin{array}{l}\text { W-T Strategy } \\
\text { Berusaha meminimalisir } \\
\text { kelemahan yang dimiiliki } \\
\text { dan menghindari } \\
\text { ancaman) } \\
\text { 1. Meningkatkan standar } \\
\text { pelayanan yang termasuk } \\
\text { kedalam produk yang akan } \\
\text { diawarkan } \\
\text { 2.Memperluas penjualan } \\
\text { secara online selalui mitra } \\
\text { grab dan sejenisnya. } \\
\text { 3. Memprioritaskana } \\
\text { kebutuhan utama dalam } \\
\text { mengelola peternakan. }\end{array}$ \\
\hline
\end{tabular}

Sumber: Hasil olah data peneliti 2022 


\section{Journal Publicuho}

ISSN 2621-1351 (online), ISSN 2685-0729 (print)

Volume 5 Number 1 (February - April 2022) pp. 1-14

Accredited SINTA SK.NOMOR 28/E/KPT/2019

Open Access at:http://ojs.uho.ac.id/index.php/PUBLICUHO/index

\section{PEMBAHASAN}

\section{Strategi keunggulan bersaing}

Strategi keunggulan bersaing UD. Baqoroh Joyo menggunakan Strategi kenggulan biaya yakni strategi yang menekankan pada keunggulan biaya. Melalui kerjasama dengan partner bisnis, Biaya promosi, Harga yang bersaing dengan produk yang dijual ada yang mentah dan ada yang siap minum,Mentah Rp 10.000 /Liter dan Rp. 20.000 / Liter untuk susu yang sudah matang dan siap minum. Harga bervariasi dalam bentuk botol mulai dari 7.000 (250 ml), 10.000 (350 ml), hingga 12.000 (500 ml) harga tersebut tidak dirubah karena dimasa pandemi semua orang mengalami kesulitan dan berada pada posisi survive di masa perekonomian yang menurun. Strategi diferensiasi : diferensiasi produk dengan menginovasikan rasa susu sapi selain original tetapi juga dengan berbagai varian rasa seperti : strawberry, coklat, vanilla, duren, mocca. Diferensiasi pelayanan dengan menyediakan wisata edukasi sapi perah dan yang terakhir ada strategi fokus bahwa target pasar dari peternakan ini adalah masyarakat sekitar (Sidoarjo, Surabaya dan Mojokerto), Cafe dan outlet minuman, serta perusahaan yang dapat dijadikan sebagai partner bisnis. UD. Baqoroh Joyo tidak melayani diluar Sidoarjo, Surabaya dan Mojokerto.

\section{Formulasi strategi}

Berdasarkan hasil rumusan strategi matriks SWOT dan perencanaan kombinasi strategi SWOT dan dianalisis dengan teknik analisis SWOT berdasarkan diagram analisis SWOT posisi perusahaan menduduki pada nilai yang paling tinggi yakni kuadran 1 (satu) dengan penerapan stategi pada SO (Strenght Opportunity). Strategi yang harus diterapkan UD. Baqoroh Joyo dalam kondisi ini adalah mendukung kebijakan pertumbuhan yang agresif (growth oriented strategy) :

Berikut ini strategi SO (Strenght Opportunity) yang dapat diterapkan perusahaan dalam menunjang strategi keunggulana bersaing untuk meningkatkan kinerja pemasaran agar dapat bersaing diantaranya :

1. Mempertahankan kualitas produk dan Meningkatkan pelayanan kepada konsumen dengan menjalin hubungan baik kepada konsumen dan meminta feedback atas pelayanan dan produk yang telah dibeli. Apabila mendapatkan penilaian yang baik hal ini bertujuan agar customer tersebut dapat merekomendasikan ke yang lain. Dan dapat juga menjadi bahan evaluasi perusahaan apabila ada yang kurang dari UD. Baqoroh Joyo.

2. Memberikan penawaran khusus baik produk/harga bagi customer dan pelanggan. Agar terciptanya loyalitas pelanggan karena perusahaan berusaha menjaga hubungan baik dengan pelanggan melalui penawaran khusus dalam pemberian harga seperti 
ISSN 2621-1351 (online), ISSN 2685-0729 (print)

harga diskon pembelian minimal (dengan ketentuan) dan juga promo special saat peluncuran produk baru/varian baru.

3. Membuat sebuah konten marketing mengenai produk dan mengulas sekitar lokasi usaha dapat dikenal lebih luas sebagai upaya strategi penetrasi pasar.

4. Menjaga dan merawat kandang, dalam upaya mendukung terciptanya tempat edukasi sapi perah yang nyaman, dan edukatif.

5. Aktif mengikuti program pemerintah guna memperluas relasi bisnis dan pangsa pasar.

6. Memprioritaskan kepuasan konsumen dengan cara terus berinovasi dari segi marketing promotion dan mengembangkan produk sesuai dengan perkembangan zaman agar bisnis tetap bertahan dan dapat berkembang.

\section{KESIMPULAN}

Berdasarkan hasil analisis penelitian yang sudah dilakukan oleh peneliti pada UD. Baqoroh Joyo dan mendapatkan kesimpulan sebagai berikut :

1. Hasil penelitian menunjukan bahwa strategi keunggulan bersaing UD. Baqoroh Joyo menggunakan Strategi kenggulan biaya yakni strategi yang menekankan pada keunggulan biaya. Melalui kerjasama dengan partner bisnis, Biaya promosi, Harga yang bersaing dengan produk yang dijual ada yang mentah dan ada yang siap minum,Mentah Rp 10.000 /Liter dan Rp. 20.000 / Liter untuk susu yang sudah matang dan siap minum. Harga bervariasi dalam bentuk botol mulai dari 7.000 (250 ml), 10.000 (350 ml), hingga 12.000 (500 ml) harga tersebut tidak dirubah karena dimasa pandemi semua orang mengalami kesulitan dan berada pada posisi survive di masa perekonomian yang menurun. Strategi diferensiasi : diferensiasi produk dengan menginovasikan rasa susu sapi selain original tetapi juga dengan berbagai varian rasa seperti : strawberry, coklat, vanilla, duren, mocca. Diferensiasi pelayanan dengan menyediakan wisata edukasi sapi perah dan yang terakhir ada strategi fokus bahwa target pasar dari peternakan ini adalah masyarakat sekitar (Sidoarjo, Surabaya dan Mojokerto), Cafe dan outlet minuman, serta perusahaan yang dapat dijadikan sebagai partner bisnis. UD. Baqoroh Joyo tidak melayani diluar Sidoarjo, Surabaya dan Mojokerto.

2. Melalui proses IFAS (Internal Strategi Factor Analysis Summary) dan EFAS (Eksternal strategy factor analysis summary) bahwa UD. Baqoroh Joyo memiliki hasil nilai skor kekuatan sebesar 2,87 kelemahan sebesar 0,28 peluang sebesar 2,63 dan ancaman 0,43 . Berdasarkan diagram hasil analisis SWOT menunjukan bahwa UD. Baqoroh Joyo berada pada Kuadran I, Pada situasi ini berarti UD. Baqoroh Joyo Perusahaan harus memaksimalkan dan menggunakan kekuatan dan peluang yang dimiliki untuk memperkuat posisi tersebut. Perusahaan akan memaksimalkan kekuatan dan 


\section{Journal Publicuho}

ISSN 2621-1351 (online), ISSN 2685-0729 (print)

Volume 5 Number 1 (February - April 2022) pp. 1-14

Accredited SINTA SK.NOMOR 28/E/KPT/2019

Open Access at:http://ojs.uho.ac.id/index.php/PUBLICUHO/index DOI: http://dx.doi.org/10.35817/jpu.v5i1.23469

peluang dari internal perusahaan untuk menghadapi kelemahan dan ancaman.Strategi yang harus diterapkan UD. Baqoroh Joyo dalam kondisi ini adalah mendukung kebijakan pertumbuhan yang agresif (growth oriented strategy). Seperti mempertahankan kualitas produk, strategi penetrasi pasar yakni dengan mencari pangsa basar yang lebih besar untuk produk susu sapi dapat melalui usaha pemasaran yang lebih gencar dengan meningkatkan promosi melalui media sosial, penawaran produk-produk dan promosi penjualan secara intensif masuk kelingkungan perusahaan dan mensupply outlet / café yang membutuhkan susu sapi untuk produk olahan yang mereka jual.

3. Berdasarkan hasil kombinasi strategi matriks analisis SWOT UD. Baqoroh Joyo harus menerapkan strategi SO (Strength Opportunities) yang dapat diterapkan perusahaan dalam menunjang strategi keunggulan bersaing untuk meningkatkan kinerja pemasaran diantaranya:

1) Mempertahankan kualitas produk dan Meningkatkan pelayanan kepada konsumen dengan menjalin hubungan baik kepada konsumen dan meminta feedback atas pelayanan dan produk yang telah dibeli.

2) Memberikan penawaran khusus baik produk/harga bagi customer dan pelanggan. Agar terciptanya loyalitas pelanggan karena perusahaan berusaha menjaga hubungan baik dengan pelanggan melalui penawaran khusus dalam pemberian harga seperti harga diskon.

3) Membuat sebuah konten marketing mengenai produk dan mengulas sekitar lokasi usaha dapat dikenal lebih luas sebagai upaya strategi penetrasi pasar.

4) Menjaga dan merawat kandang, dalam upaya mendukung terciptanya tempat edukasi sapi perah yang nyaman, dan edukatif.

5) Aktif mengikuti program pemerintah guna memperluas relasi bisnis dan pangsa pasar.

6) Memprioritaskan kepuasan konsumen dengan cara terus berinovasi dari segi marketing promotion dan mengembangkan produk sesuai dengan perkembangan zaman agar bisnis tetap bertahan dan dapat berkembang. 


\section{REFERENSI}

\section{BUKU}

Anggito,A \& Setiawan,J. 2018. Metode penelitian kualitatif, Sukabumi; CV. Jejak

Anita primastiwi,Drs.Sunardi. 2015. Pengantar Bisnis, Konsep,Strategi, dan

Arif Yusuf Hamali.2016. Pemahaman Strategi Blsnis Dan Kewirausahaan Jakarta: Prenada media Group

Hermawan, I. 2019. Metodologi penelitian pendidikan kuantitatif, kualitatif \& mixed methode. Kuningan; Hidayatul Quran kuningan. Kasus.Yogyakarta : CAPS (Center For Academic Publishing Service)

PRASOJO, L. D. (2018). MANAJEMEN STRATEGI.:UNY Press J1. Gejayan, Gg Alamanda,Kampus UNY Karangmalang Yogyakarta SS 281. UNY Press. mail: unypress.yogyakarta@gmail.com

Rangkuti,F. 2016. Teknik membedah kasus analisis SWOT. Jakarta: PT. Gramedia Pustaka Utama

Suci, Rahayu Puji. 2015. Zifatama Publisher Esensi Manajemen Strategi. Taman,Sidoarjo: Zifatama Publisher.

Sugiarto. 2017. Metodologi Penelitian Bisnis : Yogyakarta : PENERBIT ANDI

Suryanto. 2016. Perencanaan dan pengembangan bisnis : Tangerang Selatan : Universitas Terbuka

\section{JURNAL}

AN, Lutfy Adi, and Susi Hariyawati. 2017. "Strategi Bisnis Usaha Kecil Menengah Pada Pabrik Tahu Mega Jaya Di Domas Menganti Gresik." Jurnal Bisnis Indonesia 8(1): 65-72.

Fandy Tjiptono. 2008. Strategi Pemasaran,Edisi 2, Penerbit Andi,Yogyakarta.

Freddy Rangkuti,2016, Teknik Membedah Kasus Bisnis Analisis SWOT. Edisi Duapuluh Dua, Cetakan Keduapuluh Dua. Jakarta : PT Gramedia Pustaka Utama

Haji, Samsul, Rois Arifin, and M.Khairul ABS. 2017. "Pengaruh Orientasi Kewirausahaan, Inovasi Produk, Keunggulan Bersaing Terhadap Kinerja Pemasaran Usaha Cengkeh Di Bawean." Jurnal Riset Manajemen 06(02): 83-95.

Hambali, Achmad. 2021. "FORMULASI STRATEGI PENGEMBANGAN BISNIS MENGGUNAKAN PENDEKATAN BUSINESS MODEL CANVAS (BMC) DAN SWOT ANALYSIS DALAM UPAYA MENINGKATKAN DAYA SAING PADA PIRING SENG COFFEE \& CO TUNJUNGAN SURABAYA." Journal of Applied Business Administration (JABA): 1-12.

Richad Vernando. 2020. "ANALISIS STRATEGI KEUNGGULAN BERSAING YANG DITERAPKAN PT. FEDERAL INTERNATIONAL FINANCE MENURUT PERSPEKTIF ETIKA BISNIS ISLAM (Studi." : $1-94$.

SINAGA, AGUSTINA BONITA KRISDAYANTI. 2020. Skripsi Universitas Sumatera Utara Strategi Keunggulan Bersaing Kedai Kopi Warkop Opos Doloksanggul. Sumatra Utara.

Subandi. 2011. "Deskripsi Kualitatif Sebagai Satu Metode Dalam Penelitian Pertunjukan." Harmonia: Journal of Arts Research and Education 11(2): 173-79. 